\title{
A Summary of the Present Diffusionist Views on Bainite
}

\author{
W. T. Reynolds, Jr.*, H. I. Aaronson** and G. Spanos***
}

\begin{abstract}
The bainite transformation is here considered to be a nonlamellar, competitive form of eutectoid decomposition reaction, taking place by means of ledgewise diffusional growth. The differences between this diffusional, microstructurally oriented approach and a definition evolved from a shear-based transformation mechanism are summarized. The various morphologies of microstructurally defined bainite are described, and the factors affecting their growth kinetics are reviewed. Finally, explanations for the peculiarities associated with the transformation at intermediate reaction temperatures in certain alloy steels are presented.
\end{abstract}

(Received April 2, 1991)

Keywords: bainite, bainite morphology, diffusional transformation, shear transformation, austenite, ferrite, pearlite, cementite, carbon steel, alloy steel

\section{Introduction}

Inquiries into the nature of the bainite reaction have been hindered over the years by a continuing controversy over how bainite should be defined. All of the proposed models for the transformation fall into two categories: (1) displacive transformations involving a martensiticlike shear process of at least the substitutional atoms and often the interstitial atoms as well, and (2) diffusional transformations. One of these two mechanisms lies at the heart of each of the three most popular definitions of bainite: the surface relief definition, the overall reaction kinetics definition and the microstructural definition ${ }^{(1)}$. The roles of shear and diffusion in the bainite reaction have been discussed in detail in a number of reviews (see for example Refs. (2)-(7) as has the confusion over the definition of bainite ${ }^{(1)(8)(9)}$. The purpose of this overview is to describe a diffusional transformation framework upon which many of the complexities of bainite morphology and transformation kinetics can be simply explained in a self-consistent fashion. Before undertaking this integrated explication, it is necessary to consider the distinguishing features of shear and diffusional transformation mechanisms and then to apply these features to demonstrate that plate-shaped transformation products which are not martensite per se form by a diffusional mechanism.

\section{Similarities and Differences between Shear and Diffusional Transformation Mechanisms}

In the present context, "shear" and "diffusional" are used to refer to the atomic mechanism of transformation. A shear mechanism is used here to describe transfor-

* Materials Engineering Department, Virginia Polytechnic Institute and State University, Blacksburg, VA 24061-0237, USA.

** Department of Metallurgical Engineering and Materials Science, Carnegie Mellon University, Pittsburgh, PA 15213-3890, USA.

*** Physical Metallurgy Branch, Naval Research Laboratory, 4555 Overlook Avenue S.W., Washington, DC 20375-5000, USA. mations that take place by the coordinated movement of atoms across of an interphase boundary consisting of either an array of glissile dislocations or thin, alternately twinned regions. Martensite is the prototype of this mode of transformation. A diffusional mechanism is used to describe transformations whose unit atomic process is the biased, diffusional jumps of individual atoms. This is sometimes called a reconstructive transformation.

It should be noted that the term "shear" is often used to refer to a component of the transformation strain associated with a change in crystal structure irrespective of the actual transformation mechanism. This usage has introduced much confusion in the literature on the mechanisms of transformations and hence will not be used here.

Distinguishing experimentally between diffusional and shear transformation mechanisms requires considerable care. Historically, a transformation was believed to be martensitic if it conformed to the requirements of the Phenomenological Theory of Martensite Crystallography $(\mathrm{PTMC})^{(10)(11)}$. These can be summarized as follows:

(1) Precipitates formed by a martensitic mechanism must have a plate or lath morphology and exhibit an invariant plane strain surface relief.

(2) The parent and product phases are related by an atomic correspondence.

(3) The parent: product habit plane is irrational (except for the special case of fcc: hcp transformations).

(4) The orientation relationship between the parent phase and the product phase is irrational (except for fcc: hcp transformations).

(5) Internal heterogeneities are required to produce a lattice invariant deformation (except for fcc: hcp transformations).

(6) There is no composition difference between the precipitate and the matrix (except, perhaps, in interstitial alloys).

(7) There is no difference in long-range order between the parent and the product phases.

Each of the requirements of the PTMC either follows as 
a crystallographic consequence of an invariant plane strain transformation or as a direct result of the absence of substitutional diffusion. For a transformation to take place martensitically, all of these requirements must be met $^{(12)}$. On the other hand, many of these requirements are also fulfilled by diffusional transformations. Thus, conformance of a precipitate to many, or even all, of the requirements of the PTMC does not guarantee that a plate-shaped transformation product forms by a shear mechanism.

For example, diffusional transformations often produce surface reliefs (both invariant plane strain and more complex varieties ${ }^{(13)(14)}$. In addition, precipitates formed by a diffusional transformation mechanism often exhibit habit planes and orientation relationships that are predicted quite accurately ${ }^{(15)-(18)}$ by the invariant line model $^{(19)(20)}$, a theory geometrically similar to the PTMC.

The most reliable way to identify unambiguously the transformation mechanism is to determine the structure of the interphase boundary between the parent and the product phases. In order for a transformation to take place by a shear mechanism, the interphase boundary must be glissile and capable of moving in a conservative fashion $^{(2)(21)(22)}$. Diffusionally formed precipitates can have either a sessile interphase boundary structure or a glissile structure. If the interphase boundary is glissile and the precipitate conforms to all of the requirements of the PTMC, then and only then can a case be made for a shear transformation mechanism. A sessile boundary structure proves that the transformation (necessarily) takes place by a diffusional mechanism.

\section{Summary of Evidence for a Diffusional Growth Mechanism for Bainite Formation in Steel}

Support for a diffusional growth mechanism for bainite lies not so much in the ability of this approach to explain all of the complex phenomena associated with bainite as much as in the failure of a shear growth mechanism to account for so many of them. Considering ferrous bainite only, there are numerous instances where the crystallography and habit plane of bainite cannot be explained by the PTMC assuming realistic lattice invariant deformations ${ }^{(22)-(27)}$. Bainite plates lengthen and thicken at diffusion controlled rates ${ }^{(28)-(30)}$ and not at the high velocities one might expect if bainite formed by a rapid shear with subsequent partitioning of carbon. Finally, and most conclusively, the structure of the ferrite: austenite boundaries associated with proeutectoid ferrite and upper bainite plates are sessile and hence unable to move conservatively by glide ${ }^{(31)-(33)}$. For a more detailed examination of specific experimental examples critical of a shear mechanism and supporting a diffusional mechanism of bainite growth, the reader is referred to two recent detailed reviews on this topic ${ }^{(5)(6)}$.

\section{Bainite from the Generalized Microstructural Viewpoint}

Early investigators used the term "bainite" to describe microstructures that consisted of a dispersion of carbides in Widmanstätten ferrite ${ }^{(34)(35)}$. However, subsequent work revealed that a wide variety of non-lamellar ferrite: carbide microstructures is common and that restriction of the definition to a Widmanstätten morphology is unnecessarily specific. For example, a sufficient reduction in the austenite grain size can result in the replacement of the Widmanstätten morphology of bainite by that of grain boundary allotriomorphs ${ }^{(1)}$. Additionally, it was recognized that in some nonferrous eutectoid systems the higher volume fraction eutectoid phase (analogous to ferrite in steels) does not exhibit a plate or needle morphology $\mathrm{y}^{(1)(6)(36)}$. This led to a more general description of bainite in which a Widmanstätten morphology was no longer a requirement ${ }^{(1)}$. A generalized microstructural definition was thus proposed in which bainite is defined as the product of a nonlamellar, non-cooperative ${ }^{(37)(38)}$, mode of eutectoid decomposition ${ }^{(1)(4)(6)(8)}$. Although this definition does not restrict the shape of an evolving eutectoid structure-termed the external morphology of bainite-to plates, laths or needles, it does clearly distinguish between bainite and lamellar pearlite. In fact, observations of roughly equiaxed bainite nodules in both Ti-Cr alloy ${ }^{(39)-(41)}$ and in steels ${ }^{(42)(43)}$ led to the recent proposal that such equiaxed shapes are the fundamental morphology of bainite, and that Widmanstätten bainite structures form as a result of the dominating influence of one of the proeutectoid phases (e.g. proeutectoid ferrite plates or laths) ${ }^{(4)(38)}$.

On the current view, the external morphology depends upon the details of how the constituent phases nucleate and grow. That is, the extent to which the two product phases (ferrite and cementite) aid and/or interfere with each other's growth determines the external shape of the eutectoid mixture as it advances into the parent phase.

\section{External morphologies of microstructurally defined bainite}

\section{(1) Nodular bainite}

This term is used to describe bainite whose external morphology is not predetermined by the morphology of either of the proeutectoid phases. Thus, the two eutectoid phases play a nearly equal role in the evolution of the external morphology ${ }^{(38)}$. Growth of a bainite nodule occurs in roughly isotropic fashion and the final shape of the eutectoid mixture is approximately a sphere, or a portion thereof, when growth is unhindered, Fig. 1(a). For this reason, large contiguous volumes of untransformed matrix are usually required to form nodular bainite ${ }^{(6)}$. In low-carbon steels, the formation of closely spaced ferrite laths often precludes the formation of nodular bainite. Bainite nodules have been observed in hypereutectoid $\mathrm{Ti}-\mathrm{Cr}^{(39)-(41)}, \mathrm{Fe}-\mathrm{C}^{(42)(43)}$, and $\mathrm{Fe}-\mathrm{C}-\mathrm{Mn}^{(38)}$ alloys. Nodular bainite has also been observed in hypoeutectoid $\mathrm{Fe}-\mathrm{C}$ - 


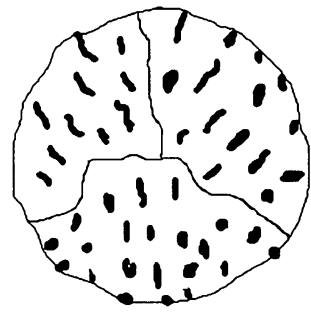

(a)

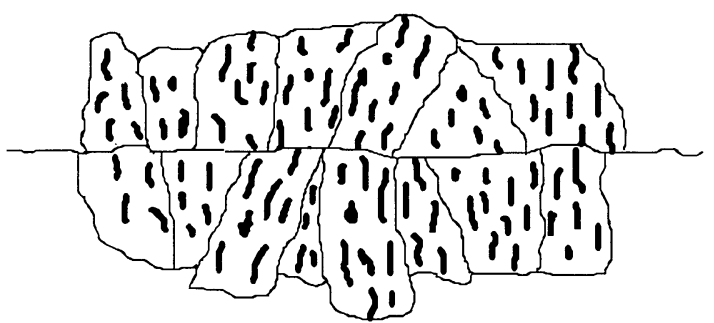

(b)

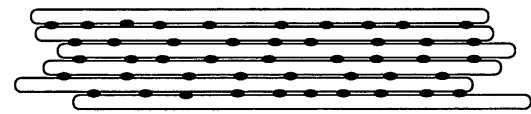

(c)

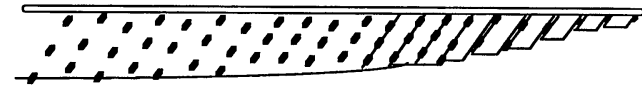

(d)

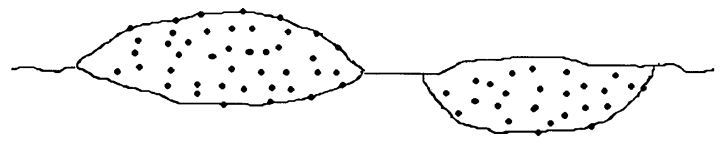

(e)

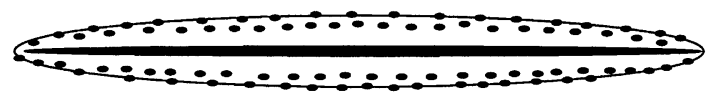

(f)

Fig. 1 Schematic illustrations of the various bainite morphologies; the white constituent represents the majority eutectoid phase (e.g. ferrite) and the dark constituent represents the minority phase (e.g. cementite). (a) Nodular bainite, (b) columnar bainite along a prior matrix grain boundary, (c) a sheaf of upper bainite laths, (d) lower bainite, (e) grain boundary allotriomorphic bainite, and (f) inverse bainite.

$\mathrm{Mo}^{(44)}$ and $\mathrm{Fe}-\mathrm{C}-\mathrm{Ni}^{(45)(46)}$ alloys. In the latter alloys, it develops after extensive precipitation of proeutectoid ferrite allotriomorphs and sideplates ${ }^{(44)(46)}$. Rather than having a spherical external shape, the nodular bainite adopts the shape of the pockets of remaining austenite in which it forms ${ }^{(44)}$.

\section{(2) Columnar bainite}

Columnar bainite is a modification of nodular bainite in which the external morphology is influenced by some microstructural feature. In steels for example, the nodular internal morphology develops between previously formed inverse bainite plate-shaped structures (described below) ${ }^{(6)(38)}$ or elongates along austenite grain boundaries ${ }^{(38)(43)(47)}$, Fig. 1(b), instead of adopting the nearly spherical external shape of nodular bainite. Columnar bainite has been observed by Nilan in $0.44 \% \mathrm{C}$ and $0.82 \% \mathrm{C}$ steels transformed under high hydrostatic pressures $^{(47)}$ and in hypereutectoid steels transformed at atmospheric pressure ${ }^{(38)(43)}$. Particularly striking examples of this bainite morphology can be seen in Figs. 10-14 of Nilan's paper ${ }^{(47)}$.

\section{(3) "Derivative" external bainite morphologies} dictated by one of the proeutectoid phases

Upper Bainite At transformation temperatures near the $A e_{3}$, the first ferrite to form adopts the grain boundary allotriomorph morphology. At transformation temperatures below the Widmanstätten start temperature, ferrite sideplates mainly evolve from grain boundary allotriomorphs; at progressively lower temperatures, the sideplates are supplemented by intragranular plates or laths when the austenite grain size is sufficiently large (usually ASTM $0-1$ or larger) $^{(48)-(50)}$. If the transformation temperature is also below the eutectoid temperature, carbide precipitation can occur in thin austenite regions between these ferrite plates (or laths) converting the microstructure to upper bainite ${ }^{(51)(52)}$ (Fig. 1(c)). Because ferrite plates (or laths) precede the formation of the carbide and the volume fraction of carbide is much less than that of ferrite, this bainite morphology is dictated by that of the proeutectoid ferrite. With further reductions in reaction temperature, single sideplates and intragranular plates are replaced by sheaves of sympathetically nucleated $^{(53)(54)}$ plates.

Lower Bainite At still lower reaction temperatures, upper bainite sheaves are replaced by sheaves with a different morphology, containing carbides that lie at an angle of 55 to 60 degrees $^{\dagger}$ to the sheaf axis ${ }^{(57)-(61)}$. On a recently proposed diffusional mechanism for the formation of lower bainite ${ }^{(57)}$, a largely carbide-free ferrite plate forms first and secondary ferrite plates then form predominantly at one broad face of the initial plate or "spine" by edge-to-face sympathetic nucleation ${ }^{(53)(54)}$.

$\dagger$ During a recent study of the lower bainite reaction, Spanos et al. concluded that the often quoted angle of $55^{(55)}$ or $60^{(56)}$ degrees is most likely somewhat too restrictive ${ }^{(57)}$. 
The broad faces of the secondary plates lie at an acute angle with respect to the longitudinal axis of the spine. Carbides form along these broad faces in the usually very narrow austenite regions remaining between adjacent secondary plates ${ }^{(57) \dagger \dagger}$ (Fig. 1(d)).

Grain Boundary Allotriomorphic Bainite In hypoeutectoid steels, carbide precipitation often occurs in association with grain boundary ferrite allotriomorphs formed below the eutectoid temperature ${ }^{(1)(53)}$. When these carbides are not formed by a cooperative growth process (as in pearlite), the composite microstructure thus formed is bainite according to the microstructural definition $^{(1)(6)}$. The circumstance that conventional upper bainite is replaced by allotriomorphic bainite with decreasing austenite grain size at a given reaction temperature $^{(1)}$ highlights the importance of the proeutectoid component's morphology in determining the overall morphology of bainite. The external shape of this form of bainite is thus obviously dictated by the proeutectoid ferrite allotriomorphs from which it develops (Fig. 1(e)).

Inverse Bainite The external morphology of this microstructure, which was originally reported by Hillert $^{(37)}$, is dominated by the proeutectoid cementite reaction. Proeutectoid cementite plates ${ }^{(37)(63)}$ or grain boundary allotriomorphs initiate inverse bainite formation ${ }^{(38)}$. The cementite is soon surrounded by a rim of ferrite, and a non-lamellar eutectoid mixture of carbide and ferrite then develops from the ferrite $\operatorname{rim}^{(38)}$ (Fig. 1(f)).

Other Terminologies Early investigators used a variety of other names to describe various microstructures which could, on current considerations, be considered to be nodular (or columnar) bainite. These include the "fan structure",(34), "degenerate nodules"(64), "pseudonodules"(65) and the "abhorescent microstructure"(66)(67). Habraken used the term "granular bainite", to refer to a composite microstructure consisting of ferrite (or microstructural bainite), martensite and retained austenite. On the generalized microstructural definition of bainite used here, "granular bainite" is a misnomer since carbide can be (and often is) absent from this structure and the presence of martensite and/or retained austenite is irrelevant ${ }^{(44)}$.

\section{Transitions between bainite morphologies}

In order to understand better how the transitions between the various bainite morphologies occur as a function of temperature and composition, it is useful to highlight some of the results and analyses of a recent investigation of the isothermal decomposition of austenite in $\mathrm{Fe}-\mathrm{C}-2 \% \mathrm{Mn}$ alloys ${ }^{(38)}$. In this study, a bainite morphology map was constructed to show the carbon concentration-temperature ranges where lower bainite, upper bainite, nodular bainite and inverse bainite are observed (Fig. 2). Calculations of the parabolic rate constants for

$\dagger$ An alternative view, more widely accepted but still contested ${ }^{(6)}$, is that the carbides precipitate from highly supersaturated ferrite as plates or rods parallel to a single habit plane within the ferrite ${ }^{(62)}$. This mechanism fails to explain why the carbides form on only one of several equivalent habit planes.

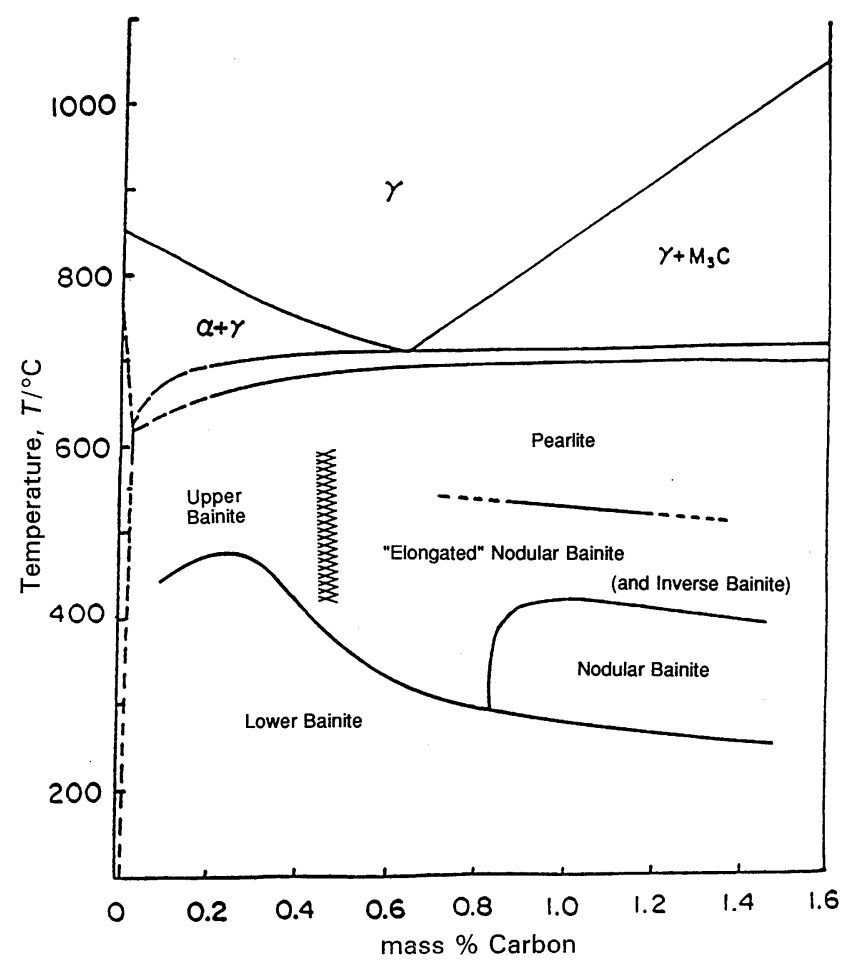

Fig. 2 Morphology map indicating temperature composition regions where the various forms of bainite predominate ${ }^{(38)}$.

growth of planar, disordered ferrite: austenite and cementite: austenite boundaries, $\alpha_{\alpha}$ and $\alpha_{c}$, and the driving forces for nucleation ${ }^{\dagger \dagger \dagger}$ of ferrite and cementite, $\Delta G_{v}^{\alpha}$ and $\Delta G_{v}^{c}$, were employed to analyze these results. It was found ${ }^{(38)}$ that lower bainite forms in the carbon concentration-temperature regime where the ratios, $\alpha_{\alpha} / \alpha_{c}$ and $\Delta G_{v}^{\alpha} / \Delta G_{v}^{c}$ are highest. With increasing temperature in the hypoeutectoid composition range, the decrease in the driving force for ferrite nucleation, $\left|\Delta G_{v}^{\alpha}\right|$, no longer allows the higher nucleation barrier, $\Delta G^{*}$, of edge-toface sympathetic nucleation to be overcome, resulting in the presence of only the face-to-face sympathetic nucleation-based morphology typical of upper bainite. Nodular bainite forms when the nucleation and growth kinetics of cementite are more nearly comparable to those of ferrite. Therefore, as the carbon content is increased (into the hypereutectoid regime), nodular bainite replaces both upper bainite and lower bainite at temperatures above approximately $275^{\circ} \mathrm{C}$ as a result of the lower values $\alpha_{\alpha} / \alpha_{c}$ and $\Delta G_{v}^{\alpha} / \Delta G_{v}^{c}$. The transition from lower bainite to nodular bainite with increasing temperature in hypereutectoid alloys (Fig. 2) can also be explained with this reasoning. The ratios, $\alpha_{\alpha} / \alpha_{c}$ and $\Delta G_{v}^{\alpha} / \Delta G_{v}^{c}$ decrease with increasing temperature in the hypereutectoid composition regime (as might be expected due to the steeper slope of the extrapolated $\gamma /(\gamma+$ cementite $)$ phase boundary relative to that of the extrapolated $\gamma /(\gamma+\alpha)$ phase boundary shown in Fig. 2) ${ }^{(38)}$. Inverse bainite formation (in addition to nodular bainite) above $400^{\circ} \mathrm{C}$ in

+ These are the Gibbs free energy changes accompanying formation of the new phases in the absence of capillarity. 
hypereutectoid alloys can be attributed to low values of $\alpha_{\alpha} / \alpha_{c}$ and $\Delta G_{v}^{\alpha} / \Delta G_{v}^{c}$ as well. In this regime, cementite plates can nucleate and grow before ferrite precipitation begins.

This model is consistent with observations of nodular bainite in hypoeutectoid alloys transformed under two different circumstances. Consider first the results Nilan obtained under conditions of high hydrostatic pressure in a $0.44 \% \mathrm{C}$ and a $0.82 \% \mathrm{C}$ steel $^{(47)}$. At a pressure of one atmosphere, the $0.44 \% \mathrm{C}$ steel is hypoeutectoid while $0.82 \% \mathrm{C}$ is a near eutectoid composition ${ }^{(47)}$. As the pressure is increased to $70 \mathrm{kbar}$, both alloys become hypereutectoid. This is reflected in the change from an upper or lower bainite morphology at 315 and $290^{\circ} \mathrm{C}$ to a columnar bainitic microstructure ${ }^{(47)}$. With respect to the current model ${ }^{(38)}$, increasing the pressure has the same effect as increasing the carbon concentration. The increased pressure raises the driving force for the nucleation and growth of cementite relative to that of ferrite, thus $\Delta G_{v}^{\alpha} / \Delta G_{v}^{c}$ and $\alpha_{\alpha} / \alpha_{c}$ decrease, hence favoring a transition from upper or lower bainite to nodular bainite.

Second, consider the nodular bainite formed in hypoeutectoid steels after precipitation of a considerable volume fraction of proeutectoid ferrite allotriomorphs and sideplates ${ }^{(44)-(46)}$. The austenite regions in which this nodular bainite forms are highly enriched in carbon rejected from adjacent proeutectoid ferrite ${ }^{(44)}$. In these regions, $\alpha_{\alpha} / \alpha_{c}$ and $\Delta G_{v}^{\alpha} / \Delta G_{v}^{c}$ are considerably smaller than in the austenite present before extensive ferrite precipitation. This allows cementite to compete much more effectively with ferrite during both nucleation and growth, and the two phases become more equal partners in the evolution of the eutectoid morphology $y^{(38)}$. Thus, there is a transition in these alloys from an upper bainite or a Widmanstätten ferrite morphology to a nodular bainite morphology in pockets of carbon-enriched austenite at the latter stages of transformation ${ }^{(44)-(46)}$.

\section{Growth Kinetics of Bainite in Steel}

\section{The ferritic component of bainite}

From a diffusional mechanism standpoint, the growth rate of microstructural bainite depends upon the growth rates (and to a varying degree, the nucleation rates as well) of the component phases. Since ferrite constitutes the major component of ferrous bainites and since peculiarities of the bainite reaction such as the incomplete reaction phenomenon are intimately associated with ferrite, the growth kinetics of ferrite can be considered of central importance to the bainite reaction in steel.

The rate at which solute species partition between ferrite and austenite and interfacial structure barriers to the migration of ferrite: austenite interphase boundaries are two factors that strongly affect the rate of ferrite growth. Interfacial structure barriers to growth arise in part from partial coherency of ferrite: austenite boundaries and the need to form growth ledges in such boundaries in order to move them ${ }^{(1)(50)}$. The influence of interfacial structure upon growth is small, albeit not eliminated, during the thickening of grain boundary ferrite allotriomorphs evidently because the ratio of the interledge spacing to ledge height is small ${ }^{(68)(69)}$. Thus, this morphology provides a convenient vehicle for investigating non-interfacial factors affecting growth. In binary $\mathrm{Fe}-\mathrm{C}$ alloys, carbon is the only partitioning solute and the growth kinetics of ferrite allotriomorphs are controlled by the rate of carbon diffusion in austenite ${ }^{(70)}$.

In ternary $\mathrm{Fe}-\mathrm{C}-\mathrm{X}$ alloys, the equilibrium concentration of the substitutional component, $\mathrm{X}$, is normally also different in ferrite and in austenite. Since X diffuses 4 to 5 orders of magnitude slower in austenite than $\mathrm{C}$, one might expect the $\mathrm{X}$ component to control the rate of ferrite growth. However, it has been demonstrated in numerous $\mathrm{Fe}-\mathrm{C}-\mathrm{X}$ alloys ${ }^{(68)}$ that growth occurs over most temperatures without partitioning of the $\mathrm{X}$ component and at rates fairly close to those predicted by paraequilibrium (growth in the absence of any migration of the $\mathrm{X}$ component, see for example Ref. (71)). Under paraequilibrium, the influence of the $\mathrm{X}$ alloying element on ferrite growth is contained in the change in the locations of the metastable $\gamma /(\gamma+\alpha)$ and $\alpha /(\alpha+\gamma)$ phase boundaries relative to their locations for comparable $\mathrm{Fe}-$ C binary alloys.

Although the paraequilibrium growth model for ferrite growth agrees reasonably well with experiment in many $\mathrm{Fe}-\mathrm{C}-\mathrm{X}$ systems, there are significant discrepancies for certain $\mathrm{X}$ elements such as $\mathrm{Mo}, \mathrm{Mn}$ and $\mathrm{Cr}^{(68)(72)}$. These elements produce growth kinetics significantly slower than those predicted by paraequilibrium. In the case of Mo, the parabolic growth constant of ferrite allotriomorphs exhibits a minimum with decreasing reaction temperature at the temperature of the bay in the TTT diagram, usually at about the temperature where, on the paraequilibrium model, it should pass through a maximum value ${ }^{(73)}$. The growth kinetics of ferrite allotriomorphs in some $\mathrm{Fe}-\mathrm{C}-\mathrm{Mo}$ alloys can exhibit as many as three distinct stages ${ }^{(74)}$. At sufficient levels of $\mathrm{C}$ and Mo, allotriomorph growth does not exhibit its usual parabolic variation with time. At higher $\mathrm{C}$ and Mo concentrations and at temperatures just above that of the bay in the TTT diagram, growth stasis, or the complete cessation of growth, can occur for finite time intervals. Since the paraequilibrinm model cannot account even qualitatively for these observations, $X$ alloying elements must be capable of exerting an additional influence upon ferrite growth. This influence has been suggested to be a solute drag-like effect (SDLE) ${ }^{(1)(50)(68)(72)}$.

The solute drag-like effect, as opposed to the more familiar solute drag effect during grain growth, is based upon the premise that nonequilibrium absorption of the $\mathrm{X}$ solute by mobile areas of $\alpha: \gamma$ interphase boundaries depresses the carbon activity in austenite in contact with the growing ferrite, thereby reducing the diffusional flux of carbon into austenite and the resulting ferrite growth kinetics $^{(68)}$. On the most recent hypothesis for the SDLE $^{(75)}$, the X solute is "swept up" by $\alpha$ : $\gamma$ boundaries as 
these boundaries advance into austenite. Elastic and/or chemical interactions of the $\mathrm{X}$ atoms with the boundary provide a binding force that sweeps the atoms along with the boundary. Since the boundary diffusivity of substitutional atoms in iron is roughly equivalent to that of carbon in austenite, these absorbed atoms can be retained by the boundary during growth. Because the equilibrium concentrations of $\mathrm{X}$ in the adjacent ferrite and austenite phases cannot be attained at the reaction times and temperatures of interest ${ }^{(76)}$, the $X$ concentration in the boundary cannot result from equilibration with both of these phases. Thus, the concentration of $\mathrm{X}$ in the $\alpha: \gamma$ boundary region must be determined by kinetic factors.

Once the $\mathrm{X}$ solute is absorbed by the boundary, however, it can influence the partitioning of the much more mobile carbon species. By equating the chemical potential of carbon in austenite and in ferrite with the chemical potential of carbon in an $\alpha: \gamma$ boundary with a specified enrichment of the $\mathrm{X}$ species, the carbon concentrations required to explain the growth kinetics in the presence of a SDLE can be calculated ${ }^{(75)}$. On the current model for the SDLE, the time dependence of the initial stage of ferrite growth kinetics reported in $\mathrm{Fe}-\mathrm{C}-\mathrm{Mo}$ alloys is suggested to result from a time dependent absorption of Mo to $\alpha: \gamma$ boundaries. Resumption of ferrite growth following termination of growth stasis is attributed, with experimental support, to reduction of the SDLE by the eventual precipitation of alloy carbides at $\alpha: \gamma$ boundaries $^{(74)(75)}$.

Direct evidence for the $\mathrm{X}$ absorption required for the operation of a SDLE effect has been found in the case of $\mathrm{Fe}-\mathrm{C}-\mathrm{Mo}$ alloys. Chemical analysis by field-ion microscopy/atom probe of an $\alpha: \gamma$ boundary in an alloy likely to exhibit a strong SDLE ${ }^{(77)}$ and by STEM in a similar alloy ${ }^{(78)}$ indicates that Mo enriches these boundaries by at least a factor of two. Contradictory results have been reported for Mn-containing alloys but these presently are considered to be inconclusive ${ }^{(6)}$.

\section{Derivative bainite morphologies}

Measurements of the growth kinetics of derivative forms of bainite have only been made in steels ${ }^{(6)}$. The growth kinetics are dominated by the majority phase, ferrite. Three independent studies on lower bainite have utilized hot stage optical microscopy to measure growth kinetics $^{(28)-(30)}$. Speich and Cohen showed that the lengthening kinetics of lower bainite plates ${ }^{\dagger+\dagger}$ formed in $\mathrm{Fe}-\mathrm{C}, \mathrm{Fe}-\mathrm{C}-\mathrm{Cr}$ and $\mathrm{Fe}-\mathrm{C}-\mathrm{Ni}$ alloys are in agreement with calculations based on the diffusion of carbon in austenite, while the thickening kinetics were interpreted in terms of carbon diffusion in (supersaturated) ferrite ${ }^{(28)}$. Yada and Ooka determined that the lengthening kinetics of lower bainite in $\mathrm{Fe}-\mathrm{C}-\mathrm{Ni}$ alloys are somewhat slower than calculations based on the diffusion of carbon in austenite in $\mathrm{Fe}-\mathrm{C}$; they attributed this difference to the

t+t† On the model of Spanos et al. ${ }^{(57)}$, what previous investigators referred to as lower bainite "plates" are actually sheaves consisting of multiple ferrite sideplates. effect(s) of nickel ${ }^{(30)}$. Smith et al. observed lower bainite growing very slowly and martensite simultaneously growing very fast in the same specimen during isothermal transformation above $M_{\mathrm{s}}$ (but presumably below $\left.M_{\mathrm{d}}\right)^{(29)}$.

Lengthening kinetics of ferrite and/or bainite plates in hypoeutectoid $\mathrm{Fe}-\mathrm{C}$ alloys also exhibit kinetics somewhat slower than those predicted by carbon diffusion controlled migration of disordered boundaries ${ }^{(83)(84)}$. This discrepancy has been ascribed to a structural barrier to the migration of the ferrite: austenite boundaries ${ }^{(84)}$.

In apparent contradiction to these results, one study reported lower bainite plate lengthening rates measured by photoemission electron microscopy that were much faster than those allowed by carbon diffusion in austenite $^{(79)}$. However, it has been suggested ${ }^{(57)}$ that these data may have been obtained from martensite plates stimulated by bainite formation at a temperature well above the $M_{\mathrm{s}}$ temperature, a phenomenon observed previously by Smith et al. ${ }^{(29)}$ and Okamoto and Oka ${ }^{(80)(81)}$.

Goodenow et al. ${ }^{(82)}$ studied lengthening kinetics of both upper and lower bainite in a $0.5 \% \mathrm{C}-0.68 \% \mathrm{Mn}-$ $0.36 \% \mathrm{Si}-8.7 \% \mathrm{Ni}$ steel and a $0.69 \% \mathrm{C}-0.85 \% \mathrm{Mn}-$ $0.70 \% \mathrm{Si}-0.86 \% \mathrm{Cr}-0.81 \% \mathrm{Mo}-1.80 \% \mathrm{Ni}$ steel. They reported a discontinuity in the lengthening rate at the transition temperature between upper and lower bainite. This change in kinetics has been attributed to differences in the detailed structure of the leading edges of upper and lower bainite plates (or sheaves), but further studies are needed to test this hypothesis ${ }^{(6)}$.

\section{Nodular bainite}

In order to model the growth of nodular bainite, in which the two eutectoid phases play a nearly equal role during growth, Lee et al. ${ }^{(4)}$ modified Hillert's analysis of pearlite growth ${ }^{(85)}$ by incorporating the ledge mechanism and by decoupling the growth rates of the two eutectoid phases. For the generalized eutectoid reaction, $\gamma \rightarrow \alpha+\beta$, this model predicts that pearlite should develop when the ratios of the ledge height to the ledge spacing at the $\alpha: \gamma$ and $\alpha: \beta$ interfaces are equal, a condition which is automatically satisfied when the Hackney-Shiflet shared growth ledge mechanism ${ }^{(86)-(88)}$ is operative (Fig. 3). When these ratios are not equal, nodular bainite should develop; the internal morphology of this structure will depend on both the ratio of the growth rate of $\alpha$ to $\beta$, $G_{\alpha} / G_{\beta}$, and on the renucleation rate of $\beta$ at $\alpha: \beta$ interfaces, ${ }_{\alpha: \gamma} J_{\beta}^{*}$ (see Fig. 4). Assuming that $G_{\alpha}>G_{\beta}$, renucleation of $\beta$ is necessary because $\beta$ will be repeatedly overrun by $\alpha$ and will have to be nucleated again, presumably on the terraces of $\alpha: \gamma$ boundaries, if the eutectoid reaction is to continue.

The only detailed analysis of experimental nodular bainite growth data appears to be the study of Lee and Aaronson $^{(41)}$ for the $\beta \rightarrow \alpha+\mathrm{TiCr}_{2}$ reaction in a $\mathrm{Ti}-25$ mass $\% \mathrm{Cr}$ alloy. Both $\alpha: \beta$ and $\mathrm{TiCr}_{2}: \beta$ interphase boundaries were found to contain growth ledges, but, unlike the shared growth ledges observed by Hackney and Shiflet ${ }^{(86)-(88)}$, the ledge height and spacings on $\alpha: \beta$ interfaces were completely independent of those on $\mathrm{TiCr}_{2}: \beta$ in- 


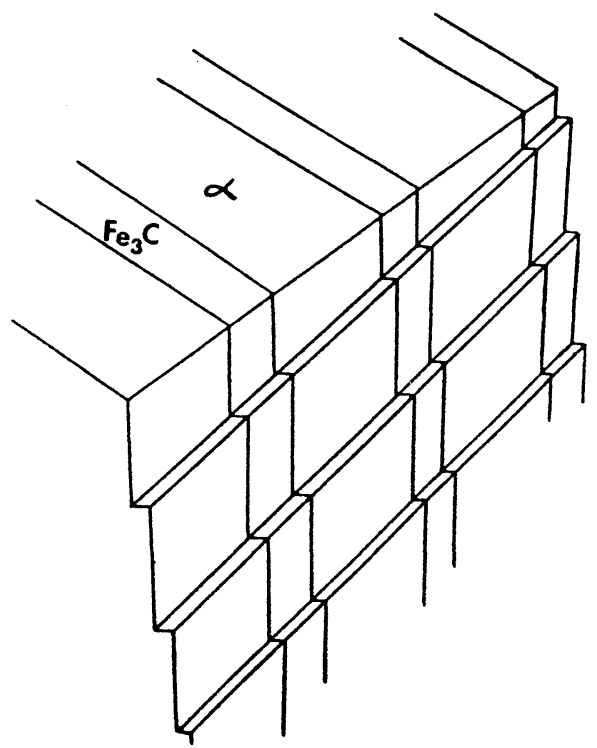

Fig. 3 Schematic of the shared growth ledge mechanism of Hackney and Shiflet ${ }^{(86)(87)}$ for the edgewise growth of pearlite.

terfaces. Despite the high volume fraction of the $\mathrm{TiCr}_{2}$ phase $(\approx 46 \%)$, the experimental growth kinetics exhibited reasonably good matching with calculations based on the Jones-Trivedi analysis ${ }^{(89)}$ of ledgewise diffusional growth for the eutectoid $\alpha$ phase (the majority product phase in this case). It was also suggested that differences in the slopes of the experimental and calculated growth rate vs. temperature curves could be due to an increasing contribution to growth from interphase boundary diffusion with decreasing temperature ${ }^{(41)}$.

\section{Overall Transformation Kinetics of Bainite}

The bainite reaction has often been defined in terms of its overall transformation kinetics. On the so-called overall reaction kinetics definition of bainite ${ }^{(90)}$, the bainite reaction is taken to have its own " $C$ " curve on the TTT diagram. In sufficiently and appropriately alloyed steels, the bainite " $C$ " curve lies below the pearlite " $C$ " curve. As the upper limiting temperature of the bainite " $C$ " curve is approached, termed the kinetic bainite start or $B_{s}$ temperature, the bainite reaction is taken to be increasingly incomplete. This characteristic is known as transformation stasis or the incomplete reaction phenomenon.

However, this description for bainite has a number of shortcomings. An obvious one is the fact that the incomplete reaction phenomenon is not general in steel. Recent findings indicate that it depends upon the types of alloying elements present and their concentrations ${ }^{(45)(75)}$. Incomplete transformation does occur in $\mathrm{Fe}-\mathrm{C}-\mathrm{Mo}$ alloys, for example, but only when the carbon and Mo concentrations exceed minimum levels. Fe-0.1 mass $\%$ $\mathrm{C}-3$ mass $\% \mathrm{Cr}^{(91)}$ and $\mathrm{Fe}-0.1$ mass $\% \mathrm{C}-3$ mass $\% \mathrm{Mn}^{(45)}$ exhibit transformation stasis whereas a 3 mass $\% \mathrm{Mn}$ alloy with 0.4 mass $\% \mathrm{C}$ does not ${ }^{(92)}$. The incomplete reaction phenomenon was not observed in several $\mathrm{Fe}-\mathrm{C}-\mathrm{Si}$, $\mathrm{Fe}-\mathrm{C}-\mathrm{Ni}$ or $\mathrm{Fe}-\mathrm{C}-\mathrm{Cu}$ alloys ${ }^{(45)(92)}$.

At least in $\mathrm{Fe}-\mathrm{C}-\mathrm{Mo}^{(74)(75)(93)}$ and $\mathrm{Fe}-\mathrm{C}-\mathrm{Cr}^{(91)}$, and probably in other systems as well, the conventional wisdom that the TTT diagram for hypoeutectoid and eutectoid steels is composed of separate pearlite and bainite " $C$ "' curves is in serious error. Little or no pearlite forms in these systems even at the temperatures of the upper " $C$ ",

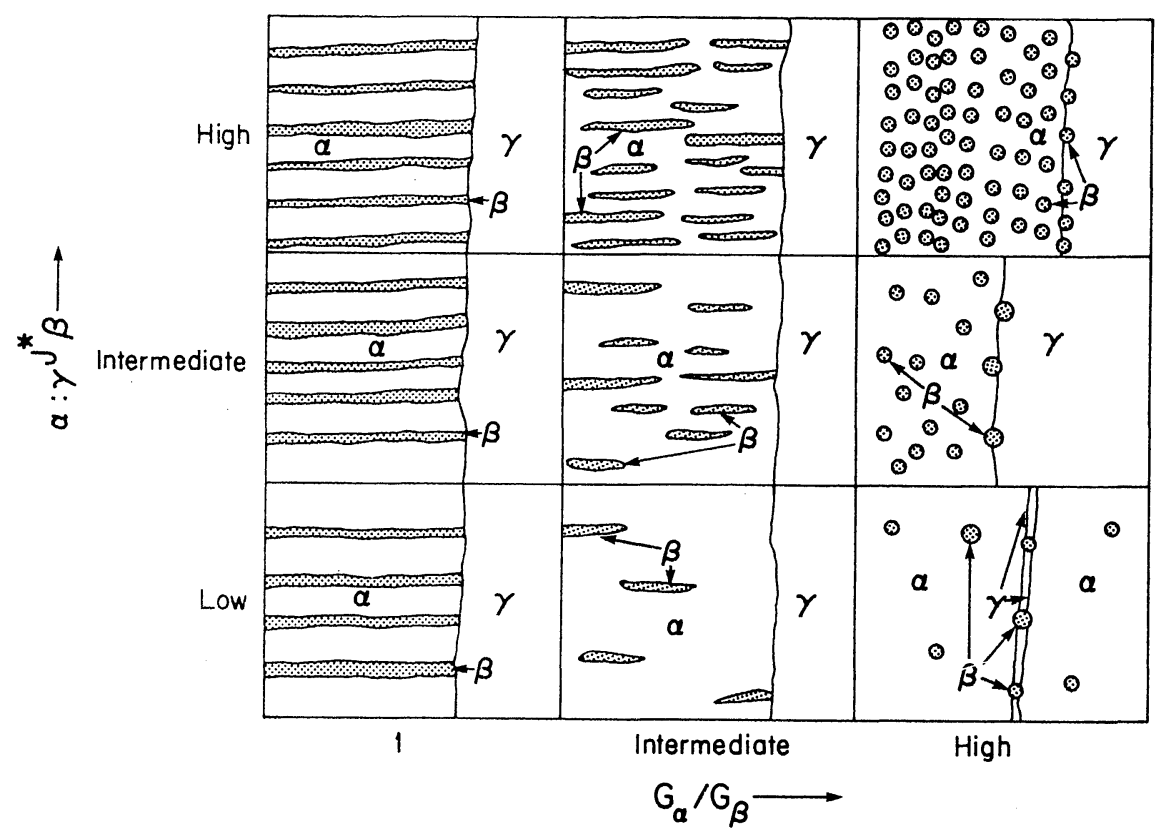

Fig. 4 Variation of the eutectoid microstructure with $G_{\alpha} / G_{\beta}$ and ${ }_{\alpha: \gamma} J_{\beta}^{*(4)}$. 


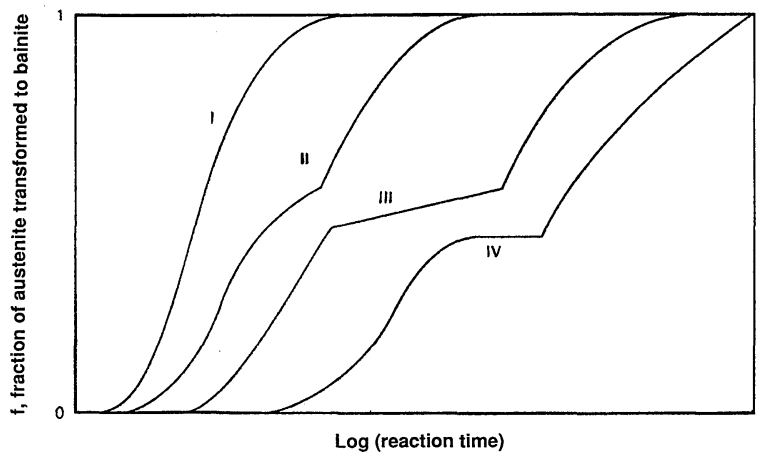

Fig. 5 Schematic of the four types of overall reaction kinetics behavior observed below the kinetic $B_{\mathrm{s}}$ in $\mathrm{Fe}-\mathrm{C}-\mathrm{Mo}$ alloys ${ }^{(6)}$.

curve. Ferrite forms first at all reaction temperatures above $M_{\mathrm{s}}$. At temperatures below the kinetic $B_{\mathrm{s}}$ temperature, the transformation kinetics (again, predominantly to ferrite) can exhibit as many as four different characteristic shapes (Fig. 5), only one of which matches the conventional description of the incomplete reaction phenomenon $^{(6)}$.

Rather than associating these observations with a reaction mechanism per se, a current view ${ }^{(6)}$ maintains that the incomplete reaction phenomenon is caused by specific alloying elements. These special elements produce a strong SDLE and change the way ferrite precipitates. Because the SDLE is solute- and composition-dependent, this approach has the potential to explain the system dependent observations on transformation stasis.

In addition to altering the growth kinetics of ferrite, the SDLE affects the morphology of ferrite. In alloys containing an element that produces a strong SDLE, i.e. elements that both segregate to $\alpha: \gamma$ boundaries and depress the activity of carbon, ferrite growth is reduced to such an extent that renucleation of ferrite at immobilized $\alpha: \gamma$ boundaries can occur. This requires sufficient undercoolings below the $A e_{3}$ to allow sympathetic nucleation of ferrite to take place. The temperature below which this occurs has been suggested to correspond to the kinetic $B_{\mathrm{s}}$ temperature ${ }^{(6)(75)}$. The degenerate morphology of ferrite ${ }^{(73)(93)}$ below the bay temperature in $\mathrm{Fe}-\mathrm{C}-\mathrm{Mo}$ alloys is a result of the change in the mode of ferrite growth from one involving the migration of individual $\alpha: \gamma$ boundaries to one in which ferrite nucleates, grows until stopped by the SDLE, and is then forced to renucleate again $^{(6)(75)}$. Diminution of the anisotropy of growth by the preferential adsorption of $\mathrm{X}$ onto the most mobile areas of $\alpha: \gamma$ boundaries has also been proposed to contribute to the degenerate shapes of individual, sympathetically nucleated ferrite crystals ${ }^{(75)}$.

The transformation sequence at temperatures below the kinetic $B_{\mathrm{s}}$ temperature is shown schematically in Fig. 6 for the case of an alloy that exhibits transformation stasis $^{(75)}$. Transformation begins with the nucleation of ferrite at austenite grain boundaries. The SDLE limits the extent to which the ferrite grows, and new ferrite crystals (sympathetically) nucleate at the immobilized

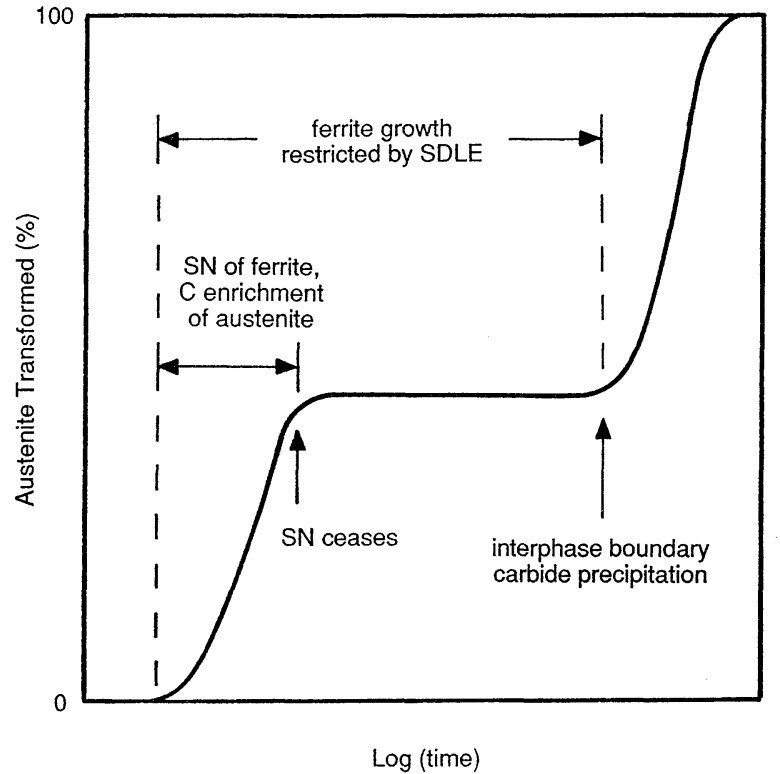

Fig. 6 Schematic representation of the transformation sequence at temperatures below the kinetic $B_{\mathrm{s}}{ }^{(75)} ; \mathrm{SN}=$ sympathetic nucleation; SDLE $=$ solute drag-like effect.

ferrite: austenite boundaries. This renucleation process continues until the surrounding austenite becomes sufficiently enriched in carbon to prevent further nucleation of ferrite.

At this point, transformation stasis begins. The growth of ferrite is prevented by the SDLE and the renucleation of ferrite is prevented by the loss of supersaturation in austenite resulting from carbon partitioning to austenite. Overall transformation effectively ceases until carbide precipitation or volume diffusion of the substitutional species relieves the SDLE on the ferrite: austenite boundaries. Limited sympathetic nucleation or slow ferrite growth accounts for the cases where transformation does not cease entirely (Fig. 5). Typically, this occurs in dilute alloys or at reaction temperatures well below the kinetic $B_{\mathrm{s}}$ where the SDLE is weaker or the driving force for ferrite growth overcomes its restraining effect.

\section{Summary}

The conclusions drawn from this overview differ only in details from a predecessor review published in $1969^{(1)}$, though the details represent significant advances in understanding the mechanisms of the phase transformations involved. The generalized microstructural definition of bainite now described as a non-lamellar, noncooperative $^{(37)}$, competitive ${ }^{(4)}$ form of eutectoid decomposition, is again advocated as the definition of bainite. Recently, however, the concern previously expressed ${ }^{(1)}$ about the blurred distinction between the bainite and pearlitc modes of eutectoid decomposition which sometimes obtains has been eliminated. The HackneyShiflet ${ }^{(86)-(88)}$ shared growth ledges mechanism now appears to be the central feature of the pearlite reactionthe lamellar, cooperative ${ }^{(37)}$, synchronous mode of eutec- 
toid decomposition. In the absence of shared growth ledges, the circumstance that both phases formed during eutectoid decomposition evidently grow by means of the ledge mechanism makes operation of the bainitic mode of eutectoid decomposition virtually inevitable. The (inter-growth ledge spacing)/(growth ledge height) ratio is likely to be different for the two phases and the growth rates of the phases will thus also differ ${ }^{(4)}$.

In respect of the view that bainite consists of plates formed by shear at temperatures usually above $M_{\mathrm{s}}$ and even above $T_{0}$, all of the transformations in substitutional alloys yielding plate-shaped products which have been studied in sufficient detail have now been shown not to fulfill one or more of the requirements ${ }^{(12)}$ of the phenomenological theory of martensite crystallography ${ }^{(5)(6)}$. Except in the V-H system ${ }^{(94)(95)}$, a similar situation obtains in interstitial alloys, particularly in stee ${ }^{(5)(6)}$. Even in the case of $\mathrm{VH}_{0.45}$ precipitation, however, the problem of synchronizing exactly the jumps of two or more $\mathrm{H}$ atoms into the hydride, which is a prerequisite for shear transformation of the crystal structures formed by the $\mathrm{V}$ atoms, can be solved only if shear occurs at nearmonatomic kinks on the risers of transformation dislocations at the broad faces of the hydride plates. The close similarity or even identity of many crystallographic and surface relief features of diffusional and martensitic transformations now appears to be related to the presence of an invariant line $\mathrm{e}^{(20)}$ in the broad faces of plates formed during both types of transformation. However, the interfacial structures associated with shear and diffusional growth are fundamentally different: the former must be glissile while the latter are usually sessile.

Recent publications ${ }^{(45)(73)(75)}$ have now provided detailed proof that the incomplete transformation phenomenon, which is central to the overall reaction kinetics definition of bainite, is absent even in many $\mathrm{Fe}-\mathrm{C}-\mathrm{X}$ systems, or is present only within certain regions of these systems. The kinetic and morphological phenomenology associated with this definition have been shown to be considerably more complex than earlier realized ${ }^{(45)(73)-(75)(91)}$. All of these phenomena appear to derive from a solute drag-like effect. Although important, their lack of generality even in steel, and their absence in all non-ferrous systems so far studied, support the earlier view ${ }^{(1)}$ that these phenomena are insufficiently general to warrant the generic appellation of "bainite".

\section{Acknowledgements}

The following agencies are gratefully acknowledged for the support of this review: WTR-the National Science Foundation through grant number DMR-8921943 and the Ford Motor Company; HIA-the U.S. Air Force Office of Scientific Research through grant number AFOSR89-0550; and GS-the U.S. Office of Naval Research.

\section{REFERENCES}

(1) H. I. Aaronson: The Mechanism of Phase Transformations in Crystalline Solids, Inst. of Metals, London, (1969), Monograph 33, p. 270.
(2) J. W. Christian: Physical Properties of Martensite and Bainite, Iron and Steel Institute, London, (1965), p. 1.

(3) J. W. Christian and D. V. Edmonds: Phase Transformations in Ferrous Alloys, TMS, Warrendale, PA, (1984), p. 293.

(4) H. J. Lee, G. Spanos, G. J. Shiflet and H. I. Aaronson: Acta Metall., 36 (1988), 1129.

(5) H. I. Aaronson, T. Furuhara, J. M. Rigsbee, W. T. Reynolds, Jr. and J. M. Howe: Metall. Trans., 21A (1990), 2369.

(6) H. I. Aaronson, W. T. Reynolds, Jr., G. J. Shiflet and G. Spanos: Metall. Trans., 21A (1990), 1343.

(7) M. Enomoto and H. Tsubakino: Bulletin Japan Inst. Metals, 28 (1989), 732.

(8) H. I. Aaronson and H. J. Lee: Scripta Metall., 21 (1987), 1011.

(9) H. I. Aaronson and W. T. Reynolds, Jr.: Phase Transformations '87, Institute of Metals, London, (1988), p. 301.

(10) M. S. Wechsler, D. S. Lieberman and T. A. Read: Trans. AIME, 197 (1953), 1503.

(11) J. S. Bowles and J. K. Mackensie: Acta Metall., 2 (1954), 129, 138, and 224.

(12) H. M. Clark and C. M. Wayman: Phase Transformations, ASM, Metals Park, OH, (1970), p. 59.

(13) Y. C. Liu and H. I. Aaronson: Acta Metall., 18 (1970), 845.

(14) H. J. Lee and H. I. Aaronson: Acta Metall., 36 (1988), 787.

(15) G. C. Weatherly, P. Humble and D. Borland: Acta Metall., 27 (1979), 1815.

(16) U. Dahmen: Acta Metall., 30 (1982), 63.

(17) U. Dahmen, P. Ferguson and K. H. Westmacott: Acta Metall., 32 (1984), 803.

(18) C. P. Luo and G. C. Weatherly: Acta Metall., 35 (1987), 1963.

(19) A. Perio, J. J. Bacmann, M. Suery and A. Eberhardt: Rev. Phys. Appl., 12 (1977), 1197.

(20) U. Dahmen: Scripta Metall., 15 (1981), 77.

(21) J. A. Kostermann: J. Less Common Metals, 28 (1972), 75.

(22) C. M. Wayman: Metallography, 8 (1975), 105.

(23) J. S. Bowles and N. F. Kennon: J. Aust. Inst. Met., 5 (1960), 106.

(24) J. D. Watson and P. G. McDougall: Acta Metall., 21 (1973), 961.

(25) G. R. Srinivasan and C. M. Wayman: Acta Metall., 16 (1968), 621.

(26) S. Hoekstra: Acta Metall., 28 (1980), 507.

(27) B. J. P. Sandvik: Metall. Trans., 13A (1982), 777.

(28) G. R. Speich and M. Cohen: Trans. Met. Soc. AIME, 218 (1960), 1050.

(29) M. F. Smith, G. R. Speich and M. Cohen: Trans. Met. Soc. AIME, 215 (1959), 528.

(30) H. Yada and T. Ooka: J. Metall. Soc. Jpn., 31 (1967), 771.

(31) J. M. Rigsbee and H. I. Aaronson: Acta Metall., 27 (1979), 365.

(32) G. R. Purdy: Scripta Metall., 21 (1987), 1035.

(33) C. Li, V. Perovic and G. R. Purdy: Phase Transformations '87, Inst. of Metals, London, (1988), p. 326.

(34) J. M. Robertson: J. Iron Steel Inst., 119 (1929), 391.

(35) E. S. Davenport and E. C. Bain: Trans. AIME, 90 (1930) 117.

(36) C. W. Spencer and D. J. Mack: The Decomposition of Austenite by Diffusional Processes, ed. by V. F. Zackay and H. I. Aaronson, Interscience, NY, (1962), p. 549.

(37) M. Hillert: Jernkont. Ann., 140 (1957), 757.

(38) G. Spanos, H. S. Fang, D. S. Sarma and H. I. Aaronson: Metall. Trans., 21A (1990), 1391.

(39) H. I. Aaronson, W. B. Triplett and G. M. Andes: Trans. AIME, 209 (1957), 1227.

(40) H. I. Aaronson, W. B. Triplett and G. M. Andes: Trans. Met. Soc. AIME, 218 (1960), 331.

(41) H. J. Lee and H. I. Aaronson: Acta Metall., 36 (1988), 1141.

(42) A. B. Greninger and R. Troiano: Trans. AIME, 140 (1940), 307.

(43) J. R. Vilella: Trans. AIME, 140 (1940), 332.

(44) W. T. Reynolds, Jr., F. Z. Li, C. K. Shui, G. J. Shiflet and H. I. Aaronson: Phase Transformations 87, ed. by G. W. Lorimer, Inst. of Metals, London (1988), p. 330.

(45) W. T. Reynolds, Jr., S. K. Liu, F. Z. Li, S. Hartfield and H. I. Aaronson: Metall. Trans., 21A (1990), 1479.

(46) G. Spanos: Metall. Trans. (1991), in press.

(47) T. G. Nilan: Transformation and Hardenability in Steels, Climax Molybdenum Co., Ann Arbor, MI, (1967), p. 57. 
(48) C. A. Dube: Ph. D. Thesis, Carnegie Inst. of Technology (1948).

(49) C. A. Dube, H. I. Aaronson and R. F. Mehl: Rev. Met., 55 (1958), 201.

(50) H. I. Aaronson, C. Laird and K. R. Kinsman: Phase Transformations, ASM, Metals Park, OH, (1970), p. 313.

(51) F. B. Pickering: Transformation and Hardenability in Steels, Climax Molybdenum Co., Ann Arbor, MI, (1967), p. 109.

(52) J. M. Oblak and R. F. Hehemann: Transformation and Hardenability in Steels, Climax Molybdenum Co., Ann Arbor, MI, (1967), p. 15.

(53) H. I. Aaronson and C. Wells: Trans. AIME, 206 (1956), 1216.

(54) E. S. K. Menon and H. I. Aaronson: Acta Metall., 35 (1987), 549.

(55) R. E. Reed-Hill: Physical Metallurgy Principles, D. Van Nostrand, New York, (1973), p. 683.

(56) R. W. K. Honeycombe, Metall. Trans., 7A (1976), 915.

(57) G. Spanos, H. S. Fang and H. I. Aaronson: Metall. Trans., 21A (1990), 1381.

(58) H. Modin and S. Modin: Jernkontorets Ann., 139 (1955), 480.

(59) Second Progress Report of Subcommittee XI of Committee E4: Trans. ASTM, 50 (1950), 444.

(60) D. H. Huang and G. Thomas: Metall. Trans., 8A (1977), 1661.

(61) G. Lai: Metall. Trans., 6A (1975), 1469.

(62) R. F. Hehemann, K. R. Kinsman and H. I. Aaronson: Metall. Trans., 3 (1972), 1077.

(63) K. R. Kinsman and H. I. Aaronson: Metall. Trans., 1 (1970), 1485.

(64) T. Lyman and A. R. Troiano: Trans. AIME, 162 (1945), 196.

(65) E. P. Klier: Trans. AIME, 162 (1945), 186.

(66) H. Jolivet: J. Iron Steel Inst., 140 (1939), 95.

(67) R. T. Howard and M. Cohen: Trans. AIME, 176 (1948), 384.

(68) J. R. Bradley and H. I. Aaronson: Metall. Trans., 12A (1981), 1729.

(69) M. Enomoto and H. I. Aaronson: Scripta Metall., 23 (1989), 1983.

(70) J. R. Bradley J. M. Rigsbee and H. I. Aaronson: Metall. Trans., 8A (1977), 323.

(71) J. B. Gilmour, G. R. Purdy and J. S. Kirkaldy: Metall. Trans., 3 (1972), 3213.

(72) K. R. Kinsman and H. I. Aaronson: Transformation and Hardenability in Steels, Climax Molybdenum Co., Ann Arbor, MI, (1967), p. 39.

(73) P. G. Boswell, K. R. Kinsman, G. J. Shiflet and H. I. Aaronson:
Mechanical Properties and Phase Transformations in Engineering Materials, TMS-AIME, Warrendale, PA, (1986), p. 445.

(74) G. J. Shiflet and H. I. Aaronson: Metall. Trans., 21A (1990), 1413.

(75) W. T. Reynolds, Jr., F. Z. Li, C. K. Shui and H. I. Aaronson: Metall. Trans., 21A (1990), 1433.

(76) H. I. Aaronson and H. A. Domian: Trans. Met. Soc. AIME, 236 (1966), 781.

(77) W. T. Reynolds, Jr., S. S. Brenner and H. I. Aaronson: Scripta Metall., 22 (1988), 1343.

(78) I. Stark and G. D. W. Smith: Phase Transformations 87, Inst. of Metals, London, (1988), p. 475.

(79) H. K. D. H. Bhadeshia: Phase Transformations in Ferrous Alloys, TMS-AIME, Warrendale, PA, (1984), p. 335.

(80) H. Okamoto and M. Oka: Metall. Trans., 17A (1986), 1113.

(81) M. Oka and H. Okamoto: Metall. Trans., 19A (1988), 447.

(82) R. H. Goodenow, S. J. Matas and R. F. Hehemann: Trans. Met. Soc. AIME, 227 (1963), 651.

(83) L. Kaufman, S. V. Radcliffe and M. Cohen: Austenite Decomposition by Diffusional Processes, Interscience, NY, (1962), p. 313.

(84) E. P. Simonen, H. I. Aaronson and R. Trivedi: Metall. Trans., 4 (1973), 1239.

(85) M. Hillert: Metall. Trans., 3 (1972), 2729.

(86) S. A. Hackney and G. J. Shiflet: Acta Metall., 35 (1987), 1007.

(87) S. A. Hackney and G. J. Shiflet: Acta Metall., 35 (1987), 1019.

(88) S. A. Hackney and G. J. Shiflet: Scripta Metall., 19 (1985), 757.

(89) G. J. Jones and R. Trivedi: J. Appl. Phys., 42 (1971), 4299.

(90) R. F. Hehemann and A. R. Troiano: Met. Prog, 70 (1956), 97.

(91) H. Goldenstein and H. I. Aaronson: Metall. Trans., 21A (1990), 1465.

(92) S. K. Liu, W. T. Reynolds, Jr., H. Hu, G. J. Shiflet and H. I. Aaronson: Metall. Trans., 16A (1985), 457.

(93) H. Tsubakino and H. I. Aaronson: Metall. Trans., 18A (1987), 2047.

(94) J. S. Bowles, B. C. Muddle and C. M. Wayman: Acta Metall., 25 (1977), 513.

(95) M. P. Cassidy, B. C. Muddle, T. E. Scott, C. M. Wayman and J. S. Bowles: Acta Metall., 25 (1977), 829.

(96) G. B. Olson, H. K. D. H. Bhadeshia and M. Cohen: Acta Metall., 37 (1989), 381.

(97) W. Jellinghaus: Arch. Eisenhuettenwes, 28 (1957), 469. 